\title{
Sarcoidosis in Jordan: A Study of the Clinical Phenotype and Disease Outcome
}

\author{
Fatima ALNAIMAT ${ }^{1}\left(\mathbb{D}\right.$, Khaled AL OWEIDAT ${ }^{2}\left(\mathbb{D}\right.$, Anas ALRWASHDEH $^{3}\left(\right.$ Al $^{2}$, Ahmad ALNASHRATI $^{3}$,

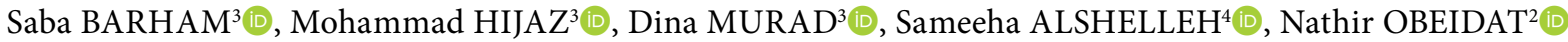 \\ ${ }^{1}$ Department of Internal Medicine, Division of Rheumatology, University of Jordan, Amman, Jordan \\ ${ }^{2}$ Department of Internal Medicine, Division of Respiratory and Sleep Medicine, University of Jordan, Amman, Jordan \\ ${ }^{3}$ Department of Internal Medicine, University of Jordan, Amman, Jordan \\ ${ }^{4}$ Department of Internal Medicine Division of Nephrology, University of Jordan, Amman, Jordan
}

\begin{abstract}
Objectives: This study aims to evaluate the clinical phenotypic features of sarcoidosis in a single-center academic hospital in Jordan.

Patients and methods: A retrospective file review was performed at an academic medical center in Jordan that included all patients diagnosed with sarcoidosis between January 2000 and December 2018. A total of 150 patients with sarcoidosis ( 38 males, 112 females; mean age $47.8 \pm 11.7$ years; range, 17 to 79 years) were evaluated. Clinical data extracted from the files included the sex of the patient, the age at time of diagnosis, diagnosis date, the season during which the diagnosis was established, and smoking history. Biopsy histopathology, spirometry, nerve conduction, echocardiography, and imaging reports including plain radiographs, ultrasonographic, magnetic resonance and computed tomography reports were reviewed. Data including laboratory values, medication usage, clinical outcomes, and morbidity/mortality were collected. Pulmonary function tests including spirometry and lung volumes along with the diffusing capacity for carbon monoxide were reviewed for the presence of restriction, obstruction or reduction in the diffusion capacity of carbon monoxide. Identification of extra-thoracic organ involvement was determined in each patient in accordance with the criteria suggested by the updated World Association of Sarcoidosis and Other Granulomatous Disorders.

Results: A total of $77.3 \%$ of the patients were diagnosed by biopsy. One case of Lofgren's syndrome was identified. Of the patients, $18.0 \%$ had isolated pulmonary sarcoidosis, $75.3 \%$ had pulmonary and extra-pulmonary sarcoidosis and $6.7 \%$ had isolated extra-pulmonary sarcoidosis while $81.3 \%$ had respiratory symptoms, mostly shortness of breath and cough. Extra-thoracic organ involvement mostly involved the musculoskeletal system (33\%) followed by the skin (20\%). Female patients had more extra-thoracic involvement but the sex difference was only statistically significant for cutaneous involvement. Of the patients, $84 \%$ received treatment while $20 \%$ had disease remission during the first two years after diagnosis and $70 \%$ required treatment beyond two years after diagnosis.

Conclusion: Various sarcoidosis clinical phenotypes are seen among Jordanian patients. Jordanian females are more affected by the disease and have more extra-thoracic involvement compared to male patients. A large number of the study patients received treatment.

Keywords: Arab, Jordan, sarcoidosis, World Association of Sarcoidosis and Other Granulomatous Disorders.
\end{abstract}

Sarcoidosis is a systemic disorder of unknown cause. It is known to mostly affect the lungs but the granulomatous reaction of sarcoidosis can affect any of the body organs like the skin, eye and lymph nodes. Young people are originally considered to be the mostly affected age group. ${ }^{1}$
However, the age at the time of diagnosis of sarcoidosis is increasing over the years in both sexes. ${ }^{2,3}$ While the exact cause of the disease is still being investigated, the influence of genes and environment was previously reported. ${ }^{4,5}$ Familial cases of sarcoidosis have been reported in the

Received: May 04, 2019 Accepted: July 16, 2019 Published online: February 07, 2020

Correspondence: Fatima Alnaimat, MD. Department of Internal Medicine, Division of Rheumatology, University of Jordan, 11942 Amman, Jordan. Tel: 00962791447845 e-mail:f.naimat@ju.edu.jo 
literature ${ }^{6}$ and family history is claimed to be one of the strongest risk factors for the disease. Patients who have at least one first-degree relative with sarcoidosis have at least fourfold increase in the chance of disease occurrence. ${ }^{7}$

The clinical presentation of patients with pulmonary sarcoidosis is variable, often asymptomatic, and sarcoidosis is brought up because of the discovery of hilar lymph nodes enlargement on routine chest radiographs. However, the most common pulmonary symptoms are cough and shortness of breath. ${ }^{8}$ Patients with extra-thoracic sarcoidosis may present with symptoms pertaining to the involved organ. In addition, the clinical features of the disease seem to vary in regard to the sex and age of the patient. ${ }^{9}$

Sarcoidosis is diagnosed in patients across the globe with variable incidences, prevalence and courses of disease among different regions and ethnicities. ${ }^{10}$ Sarcoidosis in the Middle East was previously addressed in some studies from Saudi Arabia, ${ }^{11-13}$ Kuwait, ${ }^{14}$ Oman, ${ }^{15}$ Turkey, ${ }^{6,16}$ Israel, ${ }^{17,18}$ Iran $^{19,20}$ and Egypt. ${ }^{21,22}$ In this study, we aimed to evaluate the clinical phenotypic features of sarcoidosis in a single-center academic hospital in Jordan.

\section{PATIENTS AND METHODS}

This retrospective study was carried out at the University of Jordan Hospital, a large, 599-bed academic hospital in Jordan. This hospital includes complete multidisciplinary specialties and is the main teaching hospital for the School of Medicine at the University of Jordan. The study protocol was approved by the University of Jordan Hospital Ethics Committee. A written informed consent was obtained from each patient. The study was conducted in accordance with the principles of the Declaration of Helsinki.

We identified 158 patients followed-up at the hospital's outpatient clinics under the diagnosis code of sarcoidosis after performing a search on the hospital inpatient and outpatient electronic medical records for the key word "sarcoidosis". Search was started in January $1^{\text {st }}, 2018$, and included all patients followed-up at the hospital for sarcoidosis between January 2000 and December 2018. The files of the patients were examined to extract the data pertinent to this study (see below, section of data collection). Patients were included if the sarcoidosis diagnosis was confirmed via one of the following methods: (i) Histopathologic evidence of non-caseating granuloma from lung tissues or extra-thoracic organs after exclusion of tuberculosis or other granuloma-inducing agents; (ii) the diagnosis of Lofgren's syndrome (bilateral hilar lymphadenopathy in the absence of parenchymal involvement in addition to erythema nodosum, fever and arthralgia); and (iii) patients whose biopsy was not conclusive, or was not performed because of the patient's choice, clinical contraindication or the treating physician's decision not to pursue a tissue diagnosis, but have been labeled with sarcoidosis through expert clinical and radiological assessment at the time of diagnosis and followed-up over the years for that diagnosis. The risk of tuberculosis in Jordan is relatively low and estimated to be 5.8 cases per 100,000 inhabitants per year. ${ }^{23}$ Tuberculosis was ruled out through negative acid fast bacilli and mycobacterial culture from bronchoalveolar lavage. Negative purified protein derivative testing was utilized in patients who declined bronchopscopy for bronchoalevolar lavage or when the procedure was not feasible at that time or clinically contraindicated.

Two patients were excluded because they had positive mycobacterial culture from bronchoalveolar lavage despite having noncaseating granuloma on lung biopsy, and those patients received anti-tuberculosis treatment. One pediatric patient who was nine-year-old with cutaneous sarcoidosis was excluded and five patients with wrong diagnosis were also excluded. Finally, 150 patients (38 males, 112 females; mean age $47.8 \pm 11.7$ years; range, 17 to 79 years) diagnosed over the span of 18 years were included in this study (Table 1).

Clinical data extracted from the files included the sex of the patient, the age at time of diagnosis, diagnosis date, the season during which the diagnosis was established, smoking history, defined as either never smoked or had any smoking. We reviewed the patients' clinical notes for the different specialties at the hospital outpatient clinics and any hospitalization notes to collect data regarding organ involvement by sarcoidosis. Biopsy histopathology, spirometry, nerve conduction, echocardiography, and 
Table 1. Demographic data of patients with sarcoidosis in Jordan

\begin{tabular}{lcccc}
\hline Variables & $\mathrm{n}$ & $\%$ & Mean $\pm \mathrm{SD}$ & Range \\
\hline Sex & & & & \\
$\quad$ Male & 38 & 25.3 & & \\
$\quad$ Female & 112 & 74.7 & & \\
Mean age at time of diagnosis (year) & & & $47.7 \pm 10.1$ & \\
$\quad$ All & & & $49.4 \pm 11.9$ & \\
$\quad$ Females & & & $43.6 \pm 10.1$ & \\
$\quad$ Males & 116 & 77.3 & & \\
Diagnostic method & 33 & 22 & & \\
$\quad$ Biopsy & 1 & 0.7 & & \\
$\quad$ Radiological/clinical & & & $48.2 \pm 2.6^{*}$ & \\
$\quad$ Bronchoalveolar lavage & & & $26.7 \pm 3.7$ & \\
Erythrocyte sedimentation rate (mm/h) (n=122) & & & $9.36 \pm 1.1$ & \\
C-reactive protein (mg/dL, range 0-5) (n=61) & & & $19.5 \pm 14.7$ & \\
Serum calcium (mg/dL) (n=143) & & & \\
Serum 25-hydroxy vitamin D (mg/dL) (n=67) & & & \\
\hline
\end{tabular}

SD: Standard deviation; * Age-adjusted upper limit of reference range erythrocyte sedimentation rate for each patient was calculated based on previously reported formula. ${ }^{25}$

imaging reports including plain radiographs, ultrasonographic, magnetic resonance and computed tomography (CT) reports were reviewed. Laboratory data at the time of diagnosis, when available, were reviewed including the erythrocyte sedimentation rate (ESR) where the age-adjusted upper limit of the reference range for each patient was calculated based on previously reported formula. ${ }^{24}$ In addition, C-reactive protein (CRP), 25-hydroxy vitamin $\mathrm{D}$, calcium, creatinine, liver enzymes and complete blood counts were all reviewed when available. Angiotensin converting enzyme testing was not available at the hospital and hence no data on this test were available for review. Data regarding medications usage, namely, glucocorticoids, azathioprine, methotrexate, hydroxychloroquine in addition to tumor necrosis factor-alpha (TNF- $\alpha$ ) inhibitors were collected. Data review also included patients' clinical outcome and morbidity/mortality data.

For evaluation of pulmonary sarcoidosis, the plain chest radiograph at time of diagnosis was scored, if available, according to the modified Scadding classification system where stage 0 indicates clear plain chest radiograph, stage 1 indicates bilateral hilar adenopathy in the absence of lung parenchymal, stage 2 indicates adenopathy and pulmonary infiltrates, stage 3 indicates interstitial parenchymal infiltrates in the absence of hilar adenopathy and stage 4 indicates pulmonary fibrosis. Chest $\mathrm{CT}$ scans closest to the time of diagnosis were evaluated, when available, for the presence of intrathoracic lymph nodal enlargement or parenchymal disease. Pulmonary function tests (PFTs) including spirometry and lung volumes along with the diffusing capacity for carbon monoxide (DLCO) were reviewed.

Identification of extra-thoracic organ involvement was determined in accordance with the criteria suggested by the updated World Association of Sarcoidosis and Other Granulomatous Disorders (WASOG) instrument ${ }^{25}$ (see organ involvement below). The organ symptoms or findings listed under highly probable (at least 90\% likelihood of sarcoidosis as a cause), at least probable (50-90\% likelihood of sarcoidosis as a cause) or possible (less than 50\% likelihood of sarcoidosis as a cause) but not the no consensus category of WASOG instrument were utilized in this study.

Sarcoidosis outcome score ${ }^{26}$ could not be utilized because some of the patients had disease duration of less than five years and some patients did not have follow-up imaging or PFTs available for comparison and documentation of improvement. Therefore, patients were subdivided based on their clinical disease course and outcome as the following: asymptomatic: if they received no treatment; remission: if they were tapered off the chosen treatment within two years after diagnosis; and chronic: if they continued to use the chosen medications beyond two years ${ }^{27}$ after diagnosis or 
until the time of the study enrollment. In addition, data regarding morbidities related to sarcoidosis, as deep venous thrombosis and osteoporosis, or pertaining to cardiovascular disease risk factors as diabetes, hypertension and other co-morbidities were recorded.

\section{Statistical analysis}

The IBM SPSS for windows version 22.0 software (IBM Corp., Armonk, NY, USA) was used for statistical analysis. Descriptive analysis was utilized to report frequencies and patient groups were compared using the chi-square test. A $p$ value $<0.05$ was considered as statistically significant.

\section{RESULTS}

Of the patients, $28.3 \%$ were below the age of 40 at time of diagnosis compared to $69.3 \%$ who were older than 40 years of age. Totally 97 patients were diagnosed in the years 2010-2018 and 53 patients were diagnosed in the years 2000-2009. Smoking history was missing in $50 \%$ of the patients; in the remaining $50 \%$ of the patients $(n=75), 13.3 \%$ were smokers while $36.0 \%$ never smoked.

The etiology of sarcoidosis could be related to environmental triggers and variations in the season at time of diagnosis. In those patients with available data on the season of diagnosis $(n=113)$, the season of diagnosis was mostly winter (42.5\%), followed by summer (24.8\%), spring (20.4\%) and fall (12.4\%).

Erythrocyte sedimentation rate and CRP are usually elevated in states where there is active inflammation. In this study, 115 patients (76.7\%) had their initial inflammatory markers (CRP and/or ESR) at the time of presentation available for review and $71.3 \%$ of those patients had elevated inflammatory markers. The mean ESR and CRP were $48.2 \pm 2.6$ and 26.7 \pm 3.7 , respectively (range, 0-5).

The diagnostic method was through histopathologic confirmation (77.3\%). The remaining $22.7 \%$ of the patients were diagnosed with sarcoidosis by the treating physician based on compatible clinical and radiological findings along with the presence of either one or more of the following: ankle arthritis, inflammatory arthritis, erythema nodosum, uveitis or sinusitis after exclusion of tuberculosis. Some of those patients were followed-up without the need for treatment. Further details of patients who were not diagnosed based on histopathologic confirmation can be found in the supplementary 1 material.

The most common site for biopsy in our patients was the lung (49.3\%), mostly through the transbronchial approach followed by the extra-thoracic lymph node $(8.7 \%)$ and then the skin (3.3\%). Other less frequent sites included sinonasal, orbit, liver, kidney, parotid and bone marrow. In the male cohorts, the biopsy sites were lung, intrathoraic or extra-thoracic lymph nodes. In contrast, the female cohort (the majority of the patients) had a wider variety of extra-pulmonary sites that were biopsied. One case of Lofgren's syndrome was identified in a 53-year-old male patient (represents $0.66 \%$ of the patients).

Of the patients, $92 \%$ had pulmonary involvement (Table 2), while $18.0 \%$ had isolated pulmonary sarcoidosis, $75.3 \%$ had pulmonary and extra-pulmonary sarcoidosis and only $6.7 \%$ had extra-pulmonary sarcoidosis without pulmonary involvement. Of those patients who had clinical data available regarding respiratory symptoms at the time of presentation, $18.7 \%$ did not have any respiratory symptoms compared to $81.3 \%$ that were symptomatic. Of those who were symptomatic, the most common presenting respiratory symptoms were shortness of breath and cough in $32.7 \%$, followed by isolated shortness of breath in $27.1 \%$ and isolated cough in $8.4 \%$ (Table 2). As would be expected, there was significant correlation between the presence of respiratory symptoms and the chest CT scan findings where those who were symptomatic had more parenchymal disease compared to the asymptomatic patients $(\mathrm{p}=0.009)$.

Of the patients, $74 \%$ had the initial plain chest radiograph available for evaluation. Of those patients, $49.5 \%$ were at stage 0 at time of diagnosis using the Scadding classification, while $23.4 \%$ were at stage $1,11.7 \%$ were at stage 2 and $15.3 \%$ were at stage 3 . No patients were at stage 4 at time of their presentation.

Of the patients, 92\% had their chest CT scan performed at the time of diagnosis available for evaluation. All in all, 78\% of the patients showed intrathoracic lymph node involvement and most 
Table 2. Pulmonary disease in Jordanian patients with sarcoidosis

\begin{tabular}{|c|c|c|c|c|}
\hline & Result & Frequency & $\%$ & Mean \pm SD \\
\hline Lung involvement $(\mathrm{n}=150)$ & $\begin{array}{l}\text { Positive } \\
\text { Negative }\end{array}$ & $\begin{array}{c}138 \\
12\end{array}$ & $\begin{array}{c}92 \\
8\end{array}$ & \\
\hline Chest radiography stage $(n=111)$ & $\begin{array}{l}\text { Stage } 0 \\
\text { Stage } 1 \\
\text { Stage } 2 \\
\text { Stage } 3 \\
\text { Stage } 4\end{array}$ & $\begin{array}{c}55 \\
26 \\
13 \\
17 \\
0\end{array}$ & $\begin{array}{c}49.5 \\
23.4 \\
11.7 \\
15.3 \\
0\end{array}$ & \\
\hline Chest CT scan $(n=138)$ & $\begin{array}{l}\text { Isolated parenchymal disease } \\
\text { Isolated mediastinal LAP } \\
\text { Mediastinal LAP and parenchymal disease } \\
\text { Normal }\end{array}$ & $\begin{array}{l}20 \\
36 \\
69 \\
13\end{array}$ & $\begin{array}{c}14.5 \\
26.1 \\
50 \\
9.4\end{array}$ & \\
\hline Pulmonary function test $(n=109)$ & $\begin{array}{l}\text { Normal } \\
\text { Obstructive } \\
\text { Restrictive } \\
\text { Isolated reduction in DLCO }\end{array}$ & $\begin{array}{c}41 \\
6 \\
49 \\
13\end{array}$ & $\begin{array}{c}37.6 \\
5.5 \\
45 \\
11.9\end{array}$ & \\
\hline $\mathrm{FEV}_{1}$ (liters) & & & & $2.1 \pm 0.7$ \\
\hline FVC (liters) & & & & $2.7 \pm 0.8$ \\
\hline $\mathrm{FEV}_{1} / \mathrm{FVC}$ ratio (\%) & & & & $79 \pm 7.8$ \\
\hline $\mathrm{DLCO}(\mathrm{mL} / \mathrm{min} / \mathrm{mmHg})$ & & & & $73 \pm 27.8$ \\
\hline Symptomatic lung disease $(n=107)$ & $\begin{array}{l}\text { Present } \\
\text { Absent }\end{array}$ & $\begin{array}{l}87 \\
20\end{array}$ & $\begin{array}{l}81.3 \\
18.7\end{array}$ & \\
\hline Respiratory symptoms ( $\mathrm{n}=107$ ) & $\begin{array}{l}\text { Shortness of breath and cough } \\
\text { Isolated shortness of breath } \\
\text { Isolated cough } \\
\text { Wheezes } \\
\text { Wheezes and cough } \\
\text { Shortness of breath, cough and wheezes } \\
\text { Shortness of breath and wheezes }\end{array}$ & $\begin{array}{c}25 \\
29 \\
9 \\
4 \\
4 \\
4 \\
2\end{array}$ & $\begin{array}{l}32.7 \\
27.1 \\
8.4 \\
3.7 \\
3.7 \\
3.7 \\
1.9\end{array}$ & \\
\hline
\end{tabular}

were older than 40 years of age at time of diagnosis $(p=0.013)$. Of the patients, $14.5 \%$ had isolated parenchymal disease, $26.1 \%$ had isolated mediastinal lymphadenopathy, and 50.0\% had mediastinal lymphadenopathy and parenchymal disease where the chest $\mathrm{CT}$ scan was normal in $9.4 \%$. Interestingly, $80 \%$ of the patients with stage 0 chest radiograph had evidence of intrathoracic adenopathy or parenchymal disease on the chest CT scans.

Pulmonary function tests were available for review in $72 \%$ of the patients. Of those tested, 37.6\% had normal PFT, $45.0 \%$ had restrictive pattern, $5.5 \%$ had obstructive pattern and $11.9 \%$ had isolated low DLCO. The mean forced expiratory volume in the first second $\left(\mathrm{FEV}_{1}\right)$ was $2.1 \pm 0.7$ liters, mean forced vital capacity (FVC) was $2.7 \pm 0.8$ liters, mean $\mathrm{FEV}_{1} / \mathrm{FVC}$ ratio was $79 \pm 7.8 \%$ and mean DCLCO was $73 \pm 27.8 \mathrm{~mL} / \mathrm{min} / \mathrm{mmHg}$. Of those with low DLCO, one patient only had pulmonary hypertension, diagnosed by echocardiography and not by right-sided heart catheterization. Of patients with stage 0 chest radiography, 60\% had abnormal PFT (36\% restrictive, $12 \%$ obstructive and $12 \%$ low DLCO). Of those with stage 1 , $57 \%$ had abnormal PFT (38.1\% restrictive, 9.5\% obstructive and 9.5\% low DLCO). Of those with stage 2, 87.5\% had abnormal PFT (entirely restrictive disease) and of those with stage 3 , 90\% had abnormal PFT (80\% restrictive and 10\% isolated low DLCO).

The most common site for extra-pulmonary sarcoidosis was the musculoskeletal system in $33 \%$ of the patients (mostly as arthralgia in 24\%). Most of those with musculoskeletal involvement had elevated inflammatory markers compared to those without musculoskeletal findings $(p=0.006)$.

Cutaneous involvement was next in frequency and reported in $20 \%$ of the patients, mostly as erythema nodosum (10.7\%). Statistically more 
Table 3. Frequency of extra-thoracic organ involvement by sarcoidosis in Jordanian patients

\begin{tabular}{|c|c|c|}
\hline Organ & $\%$ & Organ findings based on the WASOG instrument ${ }^{27}$ \\
\hline $\begin{array}{l}\text { Musculoskeletal }(\mathrm{n}=50) \\
\text { Females } \\
\text { Males }\end{array}$ & $\begin{array}{c}25 \\
8\end{array}$ & $\begin{array}{l}\text { Highly probable: None } \\
\text { At least probable: Nodular tenosynovitis }(2 \%, n=3) \\
\text { Possible: Arthralgia }(24 \%, n=36) \text {, myalgia }(3.33 \%, n=5) \\
\text { Other reported findings: Inflammatory polyarthritis of the peripheral joints }(n=5) \text {, isolated } \\
\text { ankle arthritis }(n=3) \text {, sacroiliitis }(n=1) \text { and multilevel vertebral bone lesions }(n=1) \text {. }\end{array}$ \\
\hline $\begin{array}{l}\text { Skin }(\mathrm{n}=30) \\
\text { Females } \\
\text { Males }\end{array}$ & $\begin{array}{c}18 \\
2\end{array}$ & $\begin{array}{l}\text { Highly probable: Lupus pernio }(0.66 \%, n=1) \text {, positive skin biopsy }(3.33 \%, n=5) \\
\text { At least probable: Erythema nodosum }(10.7 \%, n=16) \text {, subcutaneous nodules other than } \\
\text { erythema nodosum }(4 \%, n=6) \\
\text { Possible: Erythematous rash }(1.33 \%, n=2) \text {, ichthyosiform rash }(0.66 \%, n=1) \\
\text { Other reported findings: Leukocytoclastic vasculitis on skin biopsy }(n=2) \text { and } \\
\text { purpuric rash }(n=1)\end{array}$ \\
\hline $\begin{array}{l}\text { Spleen }(\mathrm{n}=25) \\
\text { Females } \\
\text { Males }\end{array}$ & $\begin{array}{c}10.6 \\
6\end{array}$ & $\begin{array}{l}\text { Highly probable: No criteria listed in the WASOG instrument } \\
\text { At least probable: Splenomegaly }(14 \%, n=21) \text {, focal lesions }(2.66 \%, n=4) \\
\text { Possible: None } \\
\text { Other reported findings: None }\end{array}$ \\
\hline $\begin{array}{l}\text { Liver }(\mathrm{n}=25) \\
\text { Females } \\
\text { Males }\end{array}$ & $\begin{array}{l}12 \\
4.7\end{array}$ & $\begin{array}{l}\text { Highly probable: No criteria listed in the WASOG instrument but } 2 \%(n=3) \text { of the patients } \\
\text { had positive liver biopsy for Sarcoidosis } \\
\text { At least probable: Hepatomegaly }(10 \%, n=18) \text {, Focal nodules }(2.66 \%, n=4) \\
\text { Possible: None } \\
\text { Other reported findings: Elevated alkaline phosphatase }(3.33 \%, n=5) \text {, transaminitis } \\
(0.66 \%, n=1)\end{array}$ \\
\hline $\begin{array}{l}\text { Extra-thoracic lymph node }(\mathrm{n}=24) \\
\text { Females } \\
\text { Males }\end{array}$ & $\begin{array}{c}12.6 \\
3.3\end{array}$ & $\begin{array}{l}\text { Highly probable: No criteria listed in the WASOG instrument but } 10 \%(\mathrm{n}=15) \text { of the patients } \\
\text { had positive biopsy for sarcoidosis from extra-thoracic lymph nodes } \\
\text { At least probable: Multiple enlarged lymph nodes without constitutional symptoms } \\
\text { (16\%, } n=24) \\
\text { Possible: None } \\
\text { Other reported findings: None }\end{array}$ \\
\hline $\begin{array}{l}\text { Eye }(\mathrm{n}=21) \\
\text { Females } \\
\text { Males }\end{array}$ & $\begin{array}{c}10 \\
4\end{array}$ & $\begin{array}{l}\text { Highly probable: Granulomatous uveitis }(6 \%, n=9) \text {, optic neuritis }(0.66 \%, n=1) \text {. Positive } \\
\text { conjunctival biopsy }(0.66 \%, n=1) \text {, positive orbital mass biopsy }(1.33 \%, n=2) \text { and positive } \\
\text { lacrimal gland biopsy }(0.66 \%, n=1) \\
\text { At least probable: } L a c r i m a l \text { gland enlargement }(1.3 \%, n=2) \\
\text { Possible: Cataract }(2.66 \%, n=4) \text {, glaucoma }(0.66 \%, n=1) \\
\text { Other reported findings: Dry eyes }(n=4) \text {, blurred vision }(n=2) \text {, conjunctival and lid } \\
\text { inflammation }(n=6) \text {, macular edema }(n=1)\end{array}$ \\
\hline $\begin{array}{l}\text { Ear, nose, throat }(\mathrm{n}=15) \\
\text { Females } \\
\text { Males }\end{array}$ & $\begin{array}{l}8 \\
2\end{array}$ & $\begin{array}{l}\text { Highly probable: No criteria listed in the WASOG instrument but four patients had positive } \\
\text { Sinonasal biopsy for non caseating granuloma } \\
\text { At least probable: None } \\
\text { Possible: Sinusitis alone was the most common finding }(8 \%, n=11) \\
\text { Other reported findings: Nasal congestion or dryness }(n=2) \text {, vocal cord dysfunction }(n=1) \text {, } \\
\text { perforated nasal septum ( } n=4) \text {, subglottic stenosis }(n=2) \text {, hearing loss }(n=1) \text { and tinnitus }(n=3) \text {. } \\
\text { All patients were tested negative for anti-neutrophil cytoplasmic antibodies (ANCAs). }\end{array}$ \\
\hline $\begin{array}{l}\text { Calcium dysregulation }(\mathrm{n}=11) \\
\text { Females } \\
\text { Males }\end{array}$ & $\begin{array}{c}5.3 \\
2\end{array}$ & $\begin{array}{l}\text { Highly probable: Hypercalcemia }(2.66 \%, \mathrm{n}=4) \\
\text { At least probable: None } \\
\text { Possible: Nephrolithiasis }(4.66 \%, \mathrm{n}=7) \\
\text { Other reported findings: Low } 25 \text {-hydroxy vitamin } \mathrm{D} \text { was seen in } 14.3 \% \text {. No data on } \\
\text { parathyroid hormone level or urinary calcium were available for review. }\end{array}$ \\
\hline $\begin{array}{l}\text { Heart }(n=8) \\
\text { Females } \\
\text { Males }\end{array}$ & $\begin{array}{c}4 \\
1.3\end{array}$ & $\begin{array}{l}\text { Highly probable: None. } \\
\text { At least probable: Ventricular arrhythmia }(1.33 \%, n=2) \\
\text { Possible: Atrial arrhythmia }(1.33 \%, n=2) \text {, reduced left ventricular ejection in the presence of } \\
\text { cardiovascular risk factors }(2.66 \%, n=4) \\
\text { Other reported findings: Palpitations }(n=3) \text { and pulmonary hypertension }(n=3)\end{array}$ \\
\hline $\begin{array}{l}\text { Salivary glands }(\mathrm{n}=5) \\
\text { Females } \\
\text { Males }\end{array}$ & $\begin{array}{c}3.3 \\
0\end{array}$ & $\begin{array}{l}\text { Highly probable: None. However, one patient had a parotid gland biopsy that showed } \\
\text { non caseating granuloma. } \\
\text { At least probable: Enlarged salivary glands }(2 \%, n=3) \\
\text { Possible: Dry mouth }(0.66 \%, n=1) \\
\text { Other reported findings: None. }\end{array}$ \\
\hline $\begin{array}{l}\text { Kidney }(\mathrm{n}=5) \\
\text { Females } \\
\text { Males }\end{array}$ & $\begin{array}{c}2 \\
1.3\end{array}$ & $\begin{array}{l}\text { Highly probable: No criteria listed in the WASOG instrument but there was one patient } \\
\text { with kidney biopsy that showed granulomatous interstitial nephritis who had uveitis and } \\
\text { negative chest radiograph and PPD test. } \\
\text { At least probable: Renal failure in the absence of cardiovascular risk factors }(0.66 \%, n=1) \\
\text { Possible: Renal failure* in the presence of cardiovascular risk factors }(2 \%, n=3) \\
\text { Other reported findings: None. }\end{array}$ \\
\hline
\end{tabular}


Table 3. Continues

\begin{tabular}{|c|c|c|}
\hline Organ & $\%$ & Organ findings based on the WASOG instrument ${ }^{27}$ \\
\hline $\begin{array}{l}\text { Nervous system }(\mathrm{n}=4) \\
\text { Females } \\
\text { Males }\end{array}$ & $\begin{array}{c}2.66 \\
0\end{array}$ & $\begin{array}{l}\text { Highly probable: Clinical syndrome consistent with granulomatous inflammation with } \\
\text { headache, cognitive decline, seizure and positive dural biopsy for granulomatous inflammation } \\
(0.66 \%, n=1) \\
\text { At least probable: Facial nerve palsy }(0.66 \%, n=1) \\
\text { Possible: Cognitive decline }(0.66 \%, n=1) \text {, seizure }(0.66 \%, n=1) \\
\text { Other reported findings: Axonal polyneuropathy }(1.3 \%, n=2) \text {, trigeminal nerve palsy } \\
(0.66 \%, n=1)\end{array}$ \\
\hline $\begin{array}{l}\text { Blood and bone marrow }(\mathrm{n}=2) \\
\text { Females } \\
\text { Males }\end{array}$ & $\begin{array}{c}1.3 \\
0\end{array}$ & $\begin{array}{l}\text { Highly probable: None as no patients underwent positron emission tomography (PET) scan. } \\
\text { However, } 1.33 \%(\mathrm{n}=2) \text { of the patients had bone marrow biopsy showing non caseating granuloma } \\
\text { At least probable: None } \\
\text { Possible: None. } \\
\text { Other reported findings: Bone marrow biopsy demonstrating hypercellular bone marrow } \\
\text { with trilineage hematopoiesis in the presence of biopsy proven sarcoidosis in another organ } \\
(\mathrm{n}=3) \text {, anemia }(\mathrm{n}=42)\end{array}$ \\
\hline
\end{tabular}

WASOG: World Association of Sarcoidosis and Other Granulomatous Disorders; PPD: Purified protein derivative; * Renal failure was diagnosed based on elevated serum creatinine above laboratory reference range (acute kidney injury) around time of diagnosis that later normalized.

females had cutaneous involvement than males with sarcoidosis $(p=0.05)$. One case of lupus pernio was reported in addition to five cases of skin biopsies that showed non-caseating granuloma.

Liver, spleen and extra-thoracic lymph nodes were almost equally involved (16\%). The vast majority of liver involvement was in the form of hepatomegaly (10\%). Furthermore, $2 \%$ of the patients had liver biopsies demonstrating noncaseating granuloma.

Ocular involvement was seen in 14\%, mostly in the form of uveitis (6\%) in addition to four patients who had orbital biopsies demonstrating non-caseating granuloma. Ear, nose and throat involvement was seen in $10 \%$ mostly as chronic sinusitis. However, four patients had non-caseating granuloma shown on tissues obtained from the sinonasal regions obtained for establishing diagnosis.

Calcium dysregulation was seen in $7.3 \%$ and heart involvement in 5.3\%. Other less frequent organ involvement included kidney and salivary gland in $3.3 \%$ of the patients and nervous system involvement in $2.66 \%$ while the least common was bone marrow involvement in $1.3 \%$. Further details of the extra-thoracic organ involvement can be seen in Table 3 which subdivides organ involvement according to the estimated probability of sarcoidosis as a cause based on the WASOG instrument.

Totally 132 patients (88\%) had their treatment course available for review. During the course of their illness, $84.8 \%$ received treatment while $15.2 \%$ did not receive any treatment. The decision about treatment was based on either the presence of symptomatic pulmonary disease or abnormal PFTs or in the case of involvement of extrathoracic organs like the eyes, central nervous system or hypercalcemia.

Most commonly patients received glucocorticoids (84.1\%) which is the standard of care treatment for this disease when indicated. Other medications were reported in the following frequencies: azathioprine in $15.2 \%$, methotrexate in $6.1 \%$, the biological agent infliximab (anti-TNF- $\alpha$ ) in $2.3 \%$, and hydroxychloroquine in $2.3 \%$ of the patients. Almost all patients with restrictive pattern on spirometry received glucocorticoids treatment compared to other patterns of PFT findings $(p<0.001)$.

All of the three patients who received hydroxychloroquine were females with musculoskeletal involvement. Details of the treatments the patients received can be found in the supplementary 2 material.

A total of 110 patients (73.3\%) were seen for clinical visits in the last two years prior to the study enrollment. The mean duration of follow-up was $9.3 \pm 5$ years. Of the patients, $18.7 \%$ were asymptomatic and required no treatment, while $6.9 \%$ were recently diagnosed less than six months before the time of study evaluation and all were on treatment with glucocorticoids. About $20 \%$ of patients had disease remission during the first two years of their disease while $70 \%$ of 
patients required treatment beyond two years after the diagnosis.

Osteoporosis was seen in about 26.4\% of patients. Patients with restrictive pattern on PFT were more likely to have a chronic pulmonary disease or to develop osteoporosis $(p<0.001)$ compared to those with obstructive pattern, isolated low DLCO or normal pulmonary function testing. Deep venous thrombosis was seen in $2.4 \%$ of the patients, while $36.2 \%$ had significant pulmonary disease with development of pulmonary fibrosis or pulmonary hypertension.

Two patients passed away during the time of follow up: one had myelodysplastic syndrome and developed chronic pulmonary aspergillosis and the other one passed away five years after her diagnosis without clear data on cause of death. However, it should be noted that follow-up data were incomplete in 25 patients since they were not seen for follow-up in the two years prior to the study enrollment period. We identified two families with sarcoidosis in our cohort: two sisters with isolated pulmonary sarcoidosis diagnosed five years apart with remission achieved in one and progressive pulmonary disease occurrence in the other one. The second family was two first cousins who both had progressive pulmonary fibrosis and ocular sarcoidosis in addition to involvement of the orbit and sinuses in one of them.

\section{DISCUSSION}

To our knowledge, this study is the first to look in the details of sarcoidosis in Jordan and the largest study of the phenotypic presentation of sarcoidosis in Arabs. Both the mean age and the season at time of diagnosis were similar to the previously reported data in the rest of the world. ${ }^{28,29}$

A large percentage of the patients had stage 0 chest radiographs at the time of diagnosis. However, $80 \%$ of those patients were found to have parenchymal lung disease on chest CT

Table 4. Organ involvement by sarcoidosis: comparison between Jordanian patients, American patients from A Case Control Etiologic Study of Sarcoidosis cohort, Olmsted county cohort and also other regional Arab people

\begin{tabular}{|c|c|c|c|c|c|c|c|c|c|}
\hline \multirow[t]{2}{*}{$\begin{array}{l}\text { Extra-thoracic organ } \\
\text { involvement }\end{array}$} & \multicolumn{2}{|c|}{$\begin{array}{l}\text { Jordanian cohort } \\
\qquad(\mathrm{n}=150)\end{array}$} & \multicolumn{2}{|c|}{$\begin{array}{l}\text { ACCESS cohort }{ }^{10} \\
(\mathrm{n}=736)\end{array}$} & \multirow{2}{*}{$\begin{array}{c}\begin{array}{c}\text { Olmsted County, } \\
\text { Minnesota }^{27}(\mathrm{n}=448)\end{array} \\
\%\end{array}$} & \multicolumn{2}{|c|}{$\begin{array}{c}\text { Kuwait } \\
(\mathrm{n}=113)\end{array}$} & \multicolumn{2}{|c|}{$\begin{array}{c}\mathrm{Oman}^{30} \\
(\mathrm{n}=83)\end{array}$} \\
\hline & $\mathrm{n}$ & $\%$ & $\mathrm{n}$ & $\%$ & & $\mathrm{n}$ & $\%$ & $\mathrm{n}$ & $\%$ \\
\hline Muscles/bone/joint & 50 & 33 & & $\begin{array}{l}0.5^{*} \\
0.4 \dagger\end{array}$ & 12 & $19^{* * *}$ & 16.8 & 26 & 31.3 \\
\hline Bone marrow & 2 & 1.3 & & 3.90 & $\mathrm{~N} / \mathrm{A}$ & \multicolumn{2}{|c|}{$\mathrm{N} / \mathrm{A}$} & \multicolumn{2}{|c|}{$\mathrm{N} / \mathrm{A}$} \\
\hline $\begin{array}{l}\text { Skin (erythema nodosum and } \\
\text { other cutaneous findings) }\end{array}$ & 30 & 20 & & 15.90 & 18 & \multicolumn{2}{|c|}{$\mathrm{N} / \mathrm{A}$} & \multicolumn{2}{|c|}{$\mathrm{N} / \mathrm{A}$} \\
\hline Erythema nodosum alone & 16 & 10.7 & 61 & 8.3 & $\mathrm{~N} / \mathrm{A}$ & 17 & 15.0 & 8 & 9.6 \\
\hline Extra-thoracic lymph nodes & 24 & 16 & & 15.20 & N/A & 11 & 9.8 & 10 & 12 \\
\hline Eye & 20 & 13.3 & & 11.80 & 7 & $14 \neq$ & 12.4 & $16 \neq$ & 19.3 \\
\hline Liver & 25 & 16.7 & & 11.50 & 6 & \multicolumn{2}{|c|}{$\mathrm{N} / \mathrm{A}$} & \multicolumn{2}{|c|}{$\mathrm{N} / \mathrm{A}$} \\
\hline Spleen & 25 & 16.7 & & 6.70 & 4 & \multicolumn{2}{|c|}{ N/A } & \multicolumn{2}{|c|}{$\mathrm{N} / \mathrm{A}$} \\
\hline Calcium dysregulation & 11 & 7.3 & & 3.70 & $\mathrm{~N} / \mathrm{A}$ & $6 \S$ & 5.3 & $13 \S$ & 15.7 \\
\hline Ear, Nose and Throat & 15 & 10 & & 3 & $\mathrm{~N} / \mathrm{A}$ & \multicolumn{2}{|c|}{$\mathrm{N} / \mathrm{A}$} & \multicolumn{2}{|c|}{$\mathrm{N} / \mathrm{A}$} \\
\hline Kidney & 5 & 3.3 & & 0.70 & 3 & \multicolumn{2}{|c|}{$\mathrm{N} / \mathrm{A}$} & \multicolumn{2}{|c|}{ N/A } \\
\hline Heart & 8 & 5.3 & & 2.30 & 1 & \multicolumn{2}{|c|}{ N/A } & 1 & 1.2 \\
\hline Nervous system & 4 & 2.66 & & 4.60 & $\mathrm{~N} / \mathrm{A}$ & \multicolumn{2}{|c|}{ N/A } & \multicolumn{2}{|l|}{2} \\
\hline Parotid/salivary & 5 & 3.3 & & 3.90 & N/A & \multicolumn{2}{|c|}{ N/A } & \multicolumn{2}{|c|}{$\mathrm{N} / \mathrm{A}$} \\
\hline
\end{tabular}

ACCESS: A Case Control Etiologic Study of Sarcoidosis; N/A: no available date; * For bone alone; ** Arthralgia only; † For muscle alone; $¥$ Uveitis only; $\S$ Hypercalcemia only. 
scans and $60 \%$ were found to have abnormal pulmonary function testing. Kobak et al. ${ }^{30}$ found typical sarcoidosis features on chest $\mathrm{CT}$ scans in all sarcoidosis patients with normal chest radiograph at time of presentation. This brings up the limitations of chest radiography scans and highlights the well-known superiority of high resolution CT scans for evaluation of diffuse infiltrative lung diseases. ${ }^{31}$

Lofgren's syndrome was rarely diagnosed in Jordan with only one case identified among the study cohort, which is similar to the data published at the "A Case Control Etiologic Study of Sarcoidosis" (ACCESS) cohort where only five cases of Lofgren's syndrome were identified among the 736 patients $(0.6 \%) .{ }^{32}$

Data from the ACCESS study showed that females with sarcoidosis tended to have more eye and neurologic involvement in addition to more cases with erythema nodosum than males with sarcoidosis. ${ }^{32}$ In our cohort, females had more extra-thoracic sarcoidosis than males (Table 3); however, this was only statistically significant for the cutaneous manifestations. Table 4 compares the extra-thoracic organ involvement in Jordanian patients to the ACCESS cohort, ${ }^{32}$ the population based study from Olmsted County, Minnesota ${ }^{29}$ and to Arab patients from Kuwait ${ }^{14}$ and Oman ${ }^{15}$ Behbehani et al. ${ }^{14}$ reported on sarcoidosis in a mixed population in Kuwait where 113 out of 142 studied patients were Arabs and the rest were Asians while Jayakrishnan et al. ${ }^{15}$ reported on 83 Arab patients from Oman.

Arthralgia was the most common extrathoracic manifestation of sarcoidosis (24\%) while it was the skin in both the ACCESS cohort and the population-based cohort study from Olmsted County, Minnesota (Table 4). Erythema nodosum was seen in $10.6 \%$ of the Jordanian patients which is close to what was observed in Oman $(9.6 \%)$ and more than what was reported in the ACCESS study (8.3\%) but less than that in Kuwait (15\%).

Liver and spleen involvement were almost equal in frequency in our cohort, which was more than the previously reported data in the ACCESS cohort and the population based study from Olmsted County, Minnesota (Table 4). Hypercalcemia was seen less frequently in Jordan compared to the other two Arab counties but close to what was reported in the ACCESS cohort (2.7\% in Jordanian patients, $5.3 \%$ in Kuwait, $15.7 \%$ in Oman and 3.7\% in the ACCESS cohort).

Furthermore, the occurrence of ocular sarcoidosis in Jordanian patients was close to the ACCESS cohort (13.3\% and $11.8 \%$, respectively) but higher than the population based study from Olmsted County, Minnesota (7\%). The studies from Oman and Kuwait only reported on uveitis, while in our cohort, there were patients who had biopsies from the lacrimal gland, orbital mass or the conjunctiva that showed non-caseating granuloma in addition to other findings that were attributed to sarcoidosis based on the WASOG instrument.

The slightly higher cardiac involvement in the Jordanian cohort could be related to the incorporation of findings that belong to the "possible" category according the WASOG instrument (Table 3) such as atrial arrhythmia or reduced left ventricular ejection fraction in the presence of cardiovascular risk factors. None of the Jordanian patients underwent cardiac magnetic resonance imaging, as it is not available at the institution.

Treatment in sarcoidosis is recommended for those patients with significant organ involvement as in progressive symptomatic lung disease, ocular disease that is refractory to topical treatment, cardiac or neurologic involvement as well as in cases of hypercalcemia. ${ }^{33}$

As would be expected, glucocorticoids were the first-line treatment choice for Jordanian patients who required systemic treatment. The vast majority of the Jordanian patients received treatment and this is similar to data on Arab patients from Oman. ${ }^{15}$ Azathioprine seemed to be a more preferred second-line treatment choice in Jordan for patients who could not take glucocorticoids or for those with progressed disease requiring further immunosuppression; this was similar to what was reported in Arab patients from Oman. ${ }^{15}$ This practice is not in line with the general recommendations by sarcoidosis experts emphasizing that methotrexate is the preferred second-line drug after glucocorticoids. ${ }^{34}$ This treatment practice could be related to the ease of administration of azathioprine as a usual daily dose rather than the weekly dosing of methotrexate, which may create confusion 
and compliance issues among patients. Also, concerns about potential conception among patients who are in the reproductive age groups make azathioprine a more appealing choice given the variation in contraception beliefs and compliance with contraception methods in this part of the world. This approach needs to be revisited given the concerns about the risk of myeloid neoplasia with azathioprine. ${ }^{35}$ TNF- $\alpha$ inhibitors biologics were not commonly utilized in Jordan with only three patients given intravenous infliximab.

Two patients passed away during the course of their disease and this small number is in agreement with what was reported in the literature, indicating that mortality in sarcoidosis is not greater than the general population. ${ }^{36}$

The current study has some limitations since it was a single-center study, which limited expanding the results on the entire Jordanian patients, and its retrospective design brought up the issue of potential bias in relation to record keeping and some missing data. Further epidemiological studies are needed in Jordan to investigate the prevalence of the disease in this part of the world.

In conclusion, various sarcoidosis phenotypes are seen among Jordanian patients. Jordanian females are more affected by the disease and have more extra-thoracic involvement compared to male patients. Moreover, a large number of the study patients received treatment, which is similar to what was previously reported in Arab patients. ${ }^{15}$

\section{Declaration of conflicting interests}

The authors declared no conflicts of interest with respect to the authorship and/or publication of this article.

\section{Funding}

The authors received no financial support for the research and/or authorship of this article.

\section{REFERENCES}

1. Rybicki BA, Major M, Popovich J Jr, Maliarik MJ, Iannuzzi MC. Racial differences in sarcoidosis incidence: a 5-year study in a health maintenance organization. Am J Epidemiol 1997;145:234-41.
2. Sawahata M, Sugiyama Y, Nakamura Y, Nakayama $\mathrm{M}$, Mato $\mathrm{N}$, Yamasawa $\mathrm{H}$, et al. Age-related and historical changes in the clinical characteristics of sarcoidosis in Japan. Respir Med 2015;109:272-8.

3. Ungprasert P, Crowson CS, Matteson EL. Influence of Gender on Epidemiology and Clinical Manifestations of Sarcoidosis: A Population-Based Retrospective Cohort Study 1976-2013. Lung 2017;195:87-91.

4. Newman LS, Rose CS, Bresnitz EA, Rossman MD, Barnard J, Frederick M, et al. A case control etiologic study of sarcoidosis: environmental and occupational risk factors. Am J Respir Crit Care Med 2004;170:1324-30.

5. Cozier YC, Ruiz-Narvaez EA, McKinnon CJ, Berman JS, Rosenberg L, Palmer JR. Fine-mapping in African-American women confirms the importance of the $10 \mathrm{p} 12$ locus to sarcoidosis. Genes Immun 2012;13:573-8.

6. Duman D, Sevim T, Sertçelik L, Akkan O, Güngör S, Yalçınsoy M, et al. Familial sarcoidosis: An analysis of twenty-eight cases. Eurasian J Pulmonol 2016;18 143-7.

7. Rossides M, Grunewald J, Eklund A, Kullberg S, Di Giuseppe D, Askling J, et al. Familial aggregation and heritability of sarcoidosis: a Swedish nested casecontrol study. Eur Respir J 2018;52. pii: 1800385

8. Judson MA. The clinical features of sarcoidosis: A comprehensive review. Clin Rev Allergy Immunol 2015;49:63-78.

9. Birnbaum AD, Rifkin LM. Sarcoidosis: sex-dependent variations in presentation and management. J Ophthalmol 2014;2014:236905.

10. Cozier YC. Assessing the worldwide epidemiology of sarcoidosis: challenges and future directions. Eur Respir J 2016;48:1545-8.

11. Al-Khouzaie TH, Al-Tawfiq JA, Al Subhi FM. Sarcoidosis in the eastern region of Saudi Arabia.Ann Thorac Med 2011;6:22-4.

12. Samman Y, Ibrahim M, Wali S. Sarcoidosis in the western region of Saudi Arabia. Sarcoidosis Vasc Diffuse Lung Dis 1999;16:215-8.

13. Alhamad EH, Alanezi MO, Idrees MM, Chaudhry MK, AlShahrani AM, Isnani A, et al. Clinical characteristics and computed tomography findings in Arab patients diagnosed with pulmonary sarcoidosis. Ann Saudi Med 2009;29:454-9.

14. Behbehani N, JayKrishnan B, Khadadah M, Hawa $\mathrm{H}$, Farah Y. Clinical presentation of sarcoidosis in a mixed population in the middle east. Respir Med 2007;101:2284-8.

15. Jayakrishnan B, Al-Busaidi N, Al-Lawati A, George J, Al-Rawas OA, Al-Mahrouqi Y, et al. Clinical features of Sarcoidosis in Oman: A report from the Middle East region. Sarcoidosis Vasc Diffuse Lung Dis 2016;33:201-8.

16. Musellim B, Kumbasar OO, Ongen G, Cetinkaya E, Turker H, Uzaslan E, et al. Epidemiological features 
of Turkish patients with sarcoidosis. Respir Med 2009;103:907-12.

17. Markevitz N, Epstein Shochet G, Levi Y, Israeli-Shani L, Shitrit D. Sarcoidosis in israel: clinical outcome status, organ involvement, and long-term follow-up. Lung 2017;195:419-24.

18. Yigla M, Badarna-Abu-Ria N, Goralnik L, Rubin AH, Weiler-Ravell D. Sarcoidosis in residents of northern Israel of Arabic and Jewish origin: a comparative study. Respirology 2006;11:586-91.

19. Lookzadeh S, Kiani A, Taghavi K, Kianersi S, Emami $\mathrm{H}$, Mirenayat $\mathrm{M}$, et al. Evaluation of the reliability and validity of the persian version of the fatigue assessment scale in Iranian sarcoidosis patients. Open Access Maced J Med Sci 2018;6:1310-4.

20. Safari S, Kiani A, Taghavi K, Naeini AS, Ghorbani J, Bashi MM, et al. Aspects of the sinonasal sarcoidosis manifestations in Iran. $\mathrm{J}$ Clin Diagnostic Res 2018;12:17-21.

21. Abdelhamid MA, Diab HS. The arrhythmic burden in patients with sarcoidosis. Is it a real concern? Egypt $\mathrm{J}$ Chest Dis Tuberc 2015;65:311-7.

22. Shouker MAH, Ghanem MM, Elashry AA, Karam KSA, Shaarawy AT, Ibraheem AM. Thoracic manifestations of sarcoidosis using multi-slice CT. IOSR J Dent Med Sci Ver II 2015;14:2279-861.

23. Hosten E, Mehta M, Andre E, Abu Rumman K, Van der Linden D. Tuberculosis contact-tracing among Syrian refugee populations: lessons from Jordan. Confl Health 2018;12:25.

24. Miller A, Green M, Robinson D. Simple rule for calculating normal erythrocyte sedimentation rate. $\mathrm{Br}$ Med J (Clin Res Ed) 1983;286:266.

25. Judson MA, Costabel U, Drent M, Wells A, Maier L, Koth L, et al. The WASOG Sarcoidosis Organ Assessment Instrument: An update of a previous clinical tool. Sarcoidosis Vasc Diffuse Lung Dis 2014;31:19-27.

26. Baughman RP, Nagai S, Balter M, Costabel U, Drent $\mathrm{M}$, du Bois $\mathrm{R}$, et al. Defining the clinical outcome status (COS) in sarcoidosis: results of WASOG Task Force. Sarcoidosis Vasc Diffuse Lung Dis
2011;28:56-64.

27. Neville E, Walker AN, James DG. Prognostic factors predicting the outcome of sarcoidosis: an analysis of 818 patients. Q J Med 1983;52:525-33.

28. Ungprasert P, Crowson CS, Matteson EL. Characteristics and long-term outcome of neurosarcoidosis: A population-based study from 1976-2013. Neuroepidemiology 2017;48:87-94.

29. UngprasertP, Crowson CS, MattesonEL. Epidemiology and clinical characteristics of sarcoidosis: an update from a population-based cohort study from Olmsted County, Minnesota. Reumatismo 2017;69:16-22.

30. Kobak S, Saydam G, Ince O, Sever F. SAT0551 Sensitivity of chest radiography in the early diagnosis of sarcoidosis: Is it really should be done? Ann Rheum Dis 2015;74:859.

31. Nunes H, Brillet PY, Valeyre D, Brauner MW, Wells AU. Imaging in Sarcoidosis. Available at: https://www. pneumonologia.gr/articlefiles/Imaging in Sarcoidosis. pdf [Accessed: May 1, 2019]

32. Baughman RP, Teirstein AS, Judson MA, Rossman MD, Yeager H Jr, Bresnitz EA, et al. Clinical characteristics of patients in a case control study of sarcoidosis. Am J Respir Crit Care Med 2001;164:1885-9.

33. Costabel U, Hunninghake GW. ATS/ERS/WASOG statement on sarcoidosis. Sarcoidosis Statement Committee. American Thoracic Society. European Respiratory Society. World Association for Sarcoidosis and Other Granulomatous Disorders. Eur Respir J 1999;14:735-7.

34. Schutt AC, Bullington WM, Judson MA. Pharmacotherapy for pulmonary sarcoidosis: a Delphi consensus study. Respir Med 2010;104:717-23.

35. Ertz-Archambault N, Kosiorek H, Taylor GE, Kelemen K, Dueck A, Castro J, et al. Association of therapy for autoimmune disease with myelodysplastic syndromes and acute myeloid leukemia. JAMA Oncol 2017;3:936-43.

36. Ungprasert P, Carmona EM, Utz JP, Ryu JH, Crowson CS, Matteson EL. Epidemiology of sarcoidosis 19462013: a population-based study. Mayo Clin Proc 2016;91:183-8. 
Supplementary 1. Clinical profile of patients diagnosed with sarcoidosis not based on biopsy

Case scenario
Radiological findings consistent with sarcoidosis, uveitis, erythema nodosum

Negative chest imaging with arthralgia and granulomatous uveitis

Radiological findings consistent with sarcoidosis and granulomatous uveitis

Negative chest imaging with sinusitis and granulomatous uveitis

Negative lung biopsy, enlarged salivary glands, myalgia and erythematous rash

Bilateral hilar enlargement without respiratory symptoms

Radiological findings consistent with sarcoidosis and ankles arthritis

Radiological findings consistent with sarcoidosis

Radiological findings consistent with sarcoidosis, erythema nodosum, and inflammatory arthritis

Radiological findings consistent with sarcoidosis, uveitis and episcleritis, erythema nodosum and arthralgia

Negative lung biopsy, radiological findings consistent with sarcoidosis and erythema nodosum

Negative lung biopsy, radiological findings consistent with sarcoidosis and chronic sinusitis

Radiological findings consistent with sarcoidosis and ankles arthritis and hypercalcemia with renal stones

Radiological findings consistent with sarcoidosis and respiratory symptoms

Radiological findings consistent with sarcoidosis, erythema nodosum, and arthralgia

Radiological findings consistent with sarcoidosis and arthralgia

Negative lung biopsy, radiological findings consistent with sarcoidosis

Radiological findings consistent with sarcoidosis, sinusitis and extra-ocular muscle inflammation

Suggestive findings of Sarcoidosis on bronchoalveolar lavage despite negative lung biopsy

Total

PPD: Purified protein derivative; AFB: Acid fast bacilli; BAL: Bronchoalveolar lavage.

34

Frequency Comments

1

1

1

1

1

1

1

5

1

1

3

1

1

6

1

2

3

2

1 Negative mycobacterial culture and AFB on BAL

Negative PPD skin testing

Negative PPD skin testing

Negative PPD skin testing

Negative PPD skin testing

Negative mycobacterial culture and AFB on BAL

Negative PPD skin testing and no treatment given

Negative PPD skin testing

Negative PPD skin testing. No treatment given

Could be Lofgren's syndrome but the treating physician did not label it as such on the chart.

Negative mycobacterial culture and AFB on BAL

Negative mycobacterial culture and AFB on BAL

Negative PPD skin testing

Negative PPD skin testing

Negative PPD skin testing

Negative PPD skin testing and no treatment given

Negative mycobacterial culture and AFB on BAL

Negative PPD skin testing 


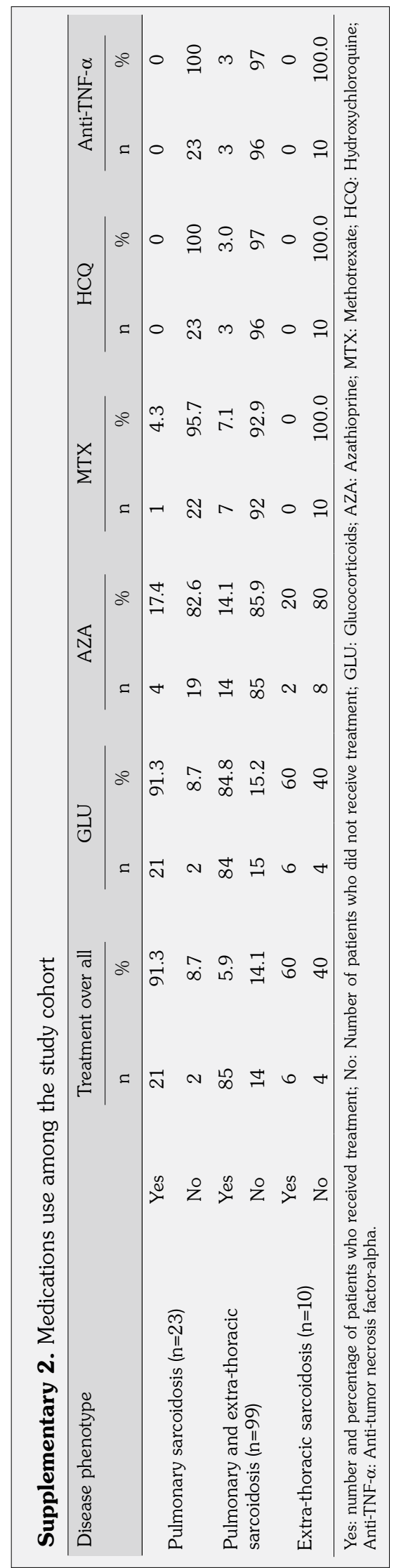

